\title{
LA DISCRIMINACIÓN INSTITUCIONAL DE VENDEDORAS AMBULANTES: LOS RETOS DE UNA «POBRE» MADRE POBRE TRABAJANDO EN LA CALLE
}

\author{
Ana E. Hasemann Lara \\ ahasemann@gmail.com \\ UNIVERSITY OF KENTUCKY
}

\begin{abstract}
RESUMEN
Las circunstancias particulares de mujeres que se dedican a la venta ambulante, su preferencia por el trabajo en el sector informal como vendedoras ambulantes y el ejercicio de la maternidad en una situación de calle, no han sido discutidas a fondo como parte del contexto urbano de Honduras. Este ensayo se adentra en la cuestión de cómo el oficio de vendedora ambulante encaja en la experiencia de vida de las mujeres pobres, madres solas o acompañadas en una ciudad atravesada por la inseguridad económica y la exclusión social.

De igual manera, se evalúa lo que significa ser madre y vendedora ambulante para dos grupos de mujeres - trece entrevistadas - que participaron en la investigación de campo que precedió el estudio, del cual se deriva este trabajo que intenta dar a conocer algunas de las justificaciones de su permanencia en el oficio que amenaza directamente su estatus de madres y de trabajadoras, empezando por situar el origen de los enfrentamientos entre estas mujeres y el Estado, y la consiguiente discriminación institucional que enfrentan como madres trabajadoras. Mencionaré ejemplos de dos entidades públicas-el Instituto Nacional de la Niñez y la Familia, IHNFA, y el gobierno municipal capitalino- que activamente ejercen la discriminación institucional.

Este ensayo se enfoca, particularmente, en la estigmatización de lo que hoy es predominantemente un espacio laboral de mujeres en América Latina dentro del sector informal: la venta ambulante. Se sugiere que estas mujeres retan y renegocian las mismas normas sociales y culturales que estructuralmente e institucionalmente las han mantenido marginadas y dentro del sector laboral donde se encuentran.
\end{abstract}

Palabras clave: Discriminación institucional, sector informal urbano, vendedoras ambulantes, feminización del sector informal, reproducción social. 


\begin{abstract}
The particular circumstances for women who work as street vendors, their preference for working in the informal sector as street vendors and their experiences as mothers in the streets have not been seriously discussed as part of the urban context in Honduras. This paper takes an in-depth look into the question of how working as street vendors fits into the life experience of poor mothers, some single and others with partners, in a city characterized by economic insecurity and social exclusion.

This paper assesses what it means to be a mother and a street vendor for two groups of women - thirteen women interviewed-participating in the field research preceding the study on which this paper is based. The author attempts to describe some of the justifications for women remaining in this economic activity — which directly threatens their status as mothers and workers. The author begins by studying the origin of conflicts between these women and the State, and the resulting institutional discrimination confronted by these working mothers. The author mentions examples of two public entities, the National Institute of Children and Family (Instituto Nacional de la Niñez y la Familia-IHNFA) and the capital city government, both of which actively engage in this institutional discrimination.

This paper focuses particularly on the stigmatization of what is currently predominantly a space in which women work in Latin America-within the informal sector as street vendors. To address this topic, the author briefly discusses how markets function as institutions and, as such, how they are structured as gender carriers. It is suggested that these women are challenging and renegotiating the very social and cultural norms that have, structurally and institutionally, kept them marginalized and working in the informal sector.
\end{abstract}

Key words: Institutional discrimination, urban informal sector, street vendors, feminization of informal sector, social reproduction. 
«Nunca olvidaré el día en que fui testigo involuntario del intento de IHNFA por quitarle la hija a Roberta. Solo tenía tres días de permanecer en este sitio y las vendedoras apenas estaban acostumbrándose a mi insistente y extraña presencia. De alguna manera, sin mediar palabras, las mujeres habían permitido que me uniera a ellas en la mediana en donde ellas se sentaban, comían, platicaban y jugaban. Precisamente, fue mientras las mujeres comían, alrededor de las 11 de la mañana, que la gente de IHNFA llegó por primera vez. Una mujer joven vestida con traje sastre inadvertidamente cruzó la calle, caminó hasta la mediana y se acercó a Roberta, quien tenía a Sofía en sus piernas mientras ambas almorzaban del mismo plato. Sofía era la más pequeña de los hijos de Roberta, tenía dos años y medio y formaba parte del escenario diario de trabajo en la calle. En un inicio, Roberta levantó la mirada hacia la mujer de traje sin ninguna reacción adversa, pero en cuestión de segundos el estado de ánimo cambió y pude escuchar la desesperación y temor en la voz de Roberta. La mujer le dijo que se llevaban a su hija y también a ella; Roberta entró en pánico, tomó en sus brazos a la niña y empezó a alejarse sin saber realmente en qué dirección, empezó a llorar mientras explicaba que no estaba haciendo nada malo, que había traído a Sofía consigo para comprarle medicina.

«La mujer del IHNFA contestó que la habían estado observando desde hacía tiempo y que sabían que Roberta había tenido a Sofía en la calle mientras trabajaba los últimos dos días. Sofía empezó a llorar inmediatamente, presintiendo que algo malo sucedía; más tarde supe que esta era una de las múltiples ocasiones en que la niña había presenciado estos encuentros. En ese momento, un carro se aproximó a la mediana y se bajaron otra mujer de traje y dos hombres armados en fatiga. Roberta entonces entregó a Sofía a su abuelo, quien se aproximó por coincidencia a la escena; este atravesó corriendo la calle a la acera opuesta y desapareció entre los peatones y el denso tráfico. Roberta corrió en la misma dirección y la gente de IHNFA tras ella. Mientras todo esto sucedía el resto de las vendedoras avisaron a sus hijos para que se fueran a sus casas. Algunas mujeres y yo seguimos a Roberta para tratar de atestiguar el incidente en lo posible y pudimos observar cómo Roberta se escabullía de sus perseguidores y desaparecía con Sofía en brazos. Todas observamos cómo Roberta escapaba zigzagueando entre las filas de transeúntes, unos esperando en la parada del bus. Sí, ese día escaparon...

«Cuando regresé a la mediana, la intersección estaba prácticamente vacía, el resto de las vendedoras habían recogido sus cosas y se habían marchado silenciosamente. Bessy, una de las vendedoras aún presentes, dijo que vendería los paquetes de chicles que le quedaban y luego también se iría; estaba preocupada porque la gente de IHNFA iba a regresar y la acosaría, como otras veces. Bessy me aconsejó irme. 
« Durante mis visitas, este sería el primero de tres estremecedores encuentros con las autoridades de IHNFA. Bessy me compartió que no era la primera vez que intentaban quitarle su hija a Roberta; ya habían puesto bajo custodia a la niña en dos ocasiones, la última hacía ocho meses, en octubre de 2006. Bessy también me explicó que la gente de IHNFA había advertido a Roberta que no trajera a Sofía a trabajar en la calle; cada vez que le devolvían la niña a Roberta, esta había perdido peso y se encontraba enferma. Lo mismo les pasaba a menudo a las otras vendedoras ambulantes, por eso Bessy mantenía a su hija en casa».

\section{INTRODUCCIÓN}

El incidente descrito arriba provocó una reconsideración de mis supuestos iniciales sobre por qué estas mujeres habían escogido la venta ambulante y cuál era el incentivo que las mantenía en el sector informal. Este ensayo aporta indicios del porqué mujeres como Roberta continúan vendiendo en las calles a pesar de su experiencia de exclusión social y discriminación institucional como «ambulantes» en el ámbito urbano hondureño. En las siguientes páginas me refiero a la exclusión social como una condición de desempleo, falta de vivienda adecuada, carencia de servicios básicos — públicos y privados—, atención médica, entre los principales. Estas condiciones prevalecen en los sectores urbanos pobres de Honduras y tal es el caso de las mujeres que hicieron posible esta investigación.

Para abordar el tema haré una breve discusión de cómo los mercados laborales son instituciones reproductoras de las discriminaciones de género. En la siguiente sección describiré detalladamente el papel que juegan dos instituciones gubernamentales locales, contribuyendo a la desmoralización y criminalización de las actividades reproductivas y productivas de las vendedoras ambulantes.

Aquí sigo la sugerencia de Safa (1995) y Bustos (1994) de distinguir entre lo objetivo y lo subjetivo en el análisis socioeconómico de la labor de mujeres. En otras palabras, haré referencia a los factores económicos, políticos, y culturales, de forma separada, no obstante que ligados a la experiencia subjetiva de cada mujer y la conciencia de que son mujeres trabajadoras con hijos. Por tanto, intento describir la violencia estructural de género predominante, su reproducción en las instituciones mencionadas y las percepciones culturales, hasta llegar a las implicaciones que tienen en la experiencia individual de incertidumbre y vulnerabilidad. 
Este ensayo se enfoca en la estigmatización de lo que hoy es predominantemente un espacio laboral de mujeres en América Latina dentro del sector informal: la venta ambulante.

No obstante lo evasiva que puede parecer esta realidad, existen instancias de autodeterminación y gestión para estas mujeres que eligen ser vendedoras ambulantes. La pregunta es si la verdadera motivación detrás de esta preferencia es que de alguna manera llena las expectativas de género y las responsabilidades inherentes al papel de reproducción, a pesar de la hostilidad hacia las mujeres que trabajan en las calle. Es necesario considerar el grado de hostilidad para identificar las razones por las que estas mujeres deciden permanecer en la venta ambulante, enfrentándose a las amenazas contra sí mismas y sus hijos.

Las justificaciones de su permanencia en este trabajo, que amenaza directamente su estatus de madres y de trabajadoras, pasan por conocer el origen de los enfrentamientos entre estas mujeres y el Estado, y la consiguiente discriminación institucional que enfrentan como madres trabajadoras. Mencionaré ejemplos de dos entidades públicas que ejercen tal discriminación institucional. Sin duda son vastos los ejemplos de instituciones que activamente discriminan y excluyen a las mujeres, estos incluyen la promulgación y aplicación de una legislación que constantemente ignora los derechos humanos de mujeres migrantes, sus privilegios conyugales y derechos civiles, los financiamientos disponibles para proyectos y organizaciones dirigidas por y para mujeres, los gobiernos locales negligentes y más. Todos estos casos añaden a la ya alta incidencia de violencia contra las mujeres, la cual va acompañada de elevadas cifras de feminicidio, que ha dado un llamado de alarma sobre el contexto mayor donde vivimos las mujeres latinoamericanas.

\section{MERCADOS INFORMALES... «INSTITUCIONES PORTADORAS DE GÉNERO»}

Las experiencias de los individuos, sus comportamientos y éxito en cuanto a las estrategias para ganarse la vida trabajando en las calles, varían dependiendo de las circunstancias locales de cada urbe (Bustos 1994, Rafaelli 2000). Roberts (1986) argumenta que:

\footnotetext{
El mercado laboral es una institución social que no solo incluye la venta de productos ... si no también una variedad de prácticas y normas que varían de lugar a lugar a pesar de las similitudes que pueden haber en sus estructuras de empleo (en Bustos 1994: 244).
}

Para analizar cómo el mercado laboral, los gobiernos locales -y las mismas vendedoras ambulantes - imponen percepciones y estereotipos acerca de la maternidad y el trabajo, se 
determinará primero cuáles son las limitantes que circunscriben a las mujeres en cuanto a opciones de trabajo y las regulaciones que amenazan sus estrategias de sobrevivencia dentro del sector informal, otra vez es un recordatorio de que los mercados laborales en Latinoamérica son, en efecto, instituciones reproductoras de las discriminaciones de género. En otras palabras, existe una marcada diferencia en el mercado de trabajo en cuanto a los tipos de trabajos disponibles para mujeres en comparación con los hombres, la brecha salarial entre hombres y mujeres que se encuentra en el mismo sector laboral es significativa y, además, se espera que los roles de género se reproduzcan en estos trabajos.

Así que cuando se trata de la oferta laboral femenina, el mercado informal en efecto opera exactamente «en la intersección de las economías productivas y reproductivas» (Elson 1999: 611). Este mismo mercado espera que las mujeres se involucren en actividades productivas que replican los roles de género asociados con el ámbito privado, es decir, que los trabajos orientados a los servicios son los que también prevalecen en el sector informal. Por ello, la participación económica de las mujeres en la esfera pública a través del sector informal no necesariamente implica «empoderamiento»o desafía las prescripciones patriarcales tradicionales sobre a quién le corresponde ser la reproductora o el que gana el sustento. El constructum familia en el contexto latinoamericano todavía encierra nociones que severamente restringen el significado de mujer-persona, womanhood, igualándolo a la identidad feminizada y las responsabilidades relacionadas con el cuidado del hogar y sus miembros.

Según Elson, el involucramiento y persistencia de las mujeres en el sector informal pudiera ser «el resultado de una harmonización [sic] hacia abajo en vez de hacia arriba» (1999: 611), esto es que las mujeres se estén conformando con menos y no busquen más, puesto que su inserción en el mercado laboral en trabajos orientados a los servicios, a través de los mecanismos de la informalidad, no rechaza o cambia automáticamente la discriminación de género reinante en la estructura del mercado, ni tampoco las concepciones locales sobre el significado de ser mujer o los valores y prejuicios asociados con una «buena madre» o el trabajo «apropiado» para una mujer.

Aunque el creciente número de mujeres activas en la fuerza laboral en Latinoamérica es significativo, no se puede interpretar como indicativo de verdadero cambio. Por una parte, porque la mayoría de estas mujeres labora en el sector informal con todas sus connotaciones negativas, lo cual deslegitimiza cualquier asociación positiva de las mujeres trabajadoras con 
las economías nacionales. Y, a pesar de que las mujeres se han convertido en miembros productivos identificables dentro de las economías nacionales, el Estado y las instituciones gubernamentales no hacen el reconocimiento debido de dicho aporte laboral y de sus costos económicos y sociales.

Los factores estructurales que influyen en el sector informal giran alrededor de un sistema socioeconómico que fomenta condiciones de pobreza, falta de oportunidades e impotencia entre aquellas personas que trabajan en este sector. Los trabajadores del sector urbano informal tienen poco o ningún acceso a mercados organizados, instituciones de crédito, centros educativos y servicios públicos (OIT 2005). Además, no reciben reconocimiento o apoyo, ni se les aplican regulaciones por parte del Estado, lo cual los ha marginado financieramente, aunque continúan funcionando productivamente en los límites de la ley y de los mercados globales. Es más, en lo que se refiere a las mujeres, en el sector informal solo se exacerba la ya aceptada invisibilidad del trabajo sin paga como una prolongación del que las mujeres ya realizan dentro del hogar. El trabajo de las mujeres fuera del marco del mercado no se toma en cuenta en las estadísticas oficiales, así como tampoco se reconoce su participación como vendedoras ambulantes dentro del sector informal. Si se reconociera, la participación de las mujeres activas en el mercado laboral y en el sector informal sería mucho mayor de lo que se ha supuesto. Es más, «el reconocer ... e incluir en las cuentas el trabajo remunerativo de las mujeres desafiaría nuestra compresión empírica ... del sector informal ... y de la economía como un todo» (Alter Chen 2001: 72). Este comentario subraya la contribución significativa que hacen las mujeres a las economías productivas de mercado. Por ende, se tendría que reconocer al sector informal como una avenida de éxito comercial y de movilidad social en las agendas de desarrollo en beneficio de un gran número de mujeres que se han convertido en el rostro de la informalidad. Además, las razones por las cuales mujeres en espacios urbanos, como Tegucigalpa, eligen ser proveedoras en el sector informal a través del ambulantaje pueden resultar en instancias importantes de autodeterminación y empoderamiento dentro de estos mercados y gobiernos locales o nacionales.

En la actualidad, las personas más vulnerables a la inestabilidad del sector informal, a las regulaciones del mercado y los gobiernos, siguen siendo las mujeres, así como los niños y los jóvenes (Takemi 2002). No es una coincidencia que sean mujeres las más prevalentes en el sector informal, usualmente como generadoras de su propio empleo en el sector de 
servicios -e. g. la venta ambulante- Entre 1990 y 1999, el sector informal creció casi 4\%, empleando a $61 \%$ de la población activa de Honduras. Además, la fuerza laboral femenina se incrementó 5\% dentro del sector informal, sumándose a los dos tercios — de la oferta nacional - de trabajadoras ya existentes en este sector de la economía. La mayoría de las mujeres involucradas en este sector son trabajadoras independientes (50\%), seguido por trabajadoras domésticas (14\%) y 7\% en microempresas. En 1999, 67.7\% del sector informal de Honduras era representado por mujeres. Si partimos de estas cifras, parece claro que el crecimiento del empleo femenino en el sector informal demuestra que este tipo de economía es «por excelencia, la esponja que absorbe el trabajo femenino» (CDM 2005: 56-57).

Las circunstancias descritas antes limitan las opciones de las mujeres en el mercado laboral y las encasillan en situaciones de mayor vulnerabilidad, inestabilidad y prejuicios. Esto es lo que Pincus (1996) ha definido como discriminación estructural, dado que el funcionamiento del mercado no supone a priori que se produzcan efectos negativos para las mujeres. En otras palabras, se asume que esta latente y persistente discriminación de género se encuentra imbuida en la organización social y la dinámica de las instituciones, mientras que la discriminación que se ejerce en el ámbito estructural se califica como «neutral en su intención ... simplemente es la forma usual de hacer negocios». Esta discriminación estructural, como la ejercida por los mercados «portadores de género» contra las mujeres, como las vendedoras ambulantes, es aquella cuyos valores culturales básicos, principios fundamentales de organización social y políticas resultantes, son representados por las instancias locales de gobierno, como IHNFA y gobierno municipal, y dan lugar a las experiencias negativas de las madres que trabajan en las calles.

De acuerdo con Pincus (1996), el IHNFA y la municipalidad practican discriminación institucional. Como se mostrará abajo, las leyes, mandatos y gerencia de estas instituciones locales, aprueban y legitiman la subordinación de la mujer. A la vez, las actividades y políticas de estas instituciones son disculpadas por la sociedad civil en su mayor parte. La discriminación que estas instituciones ejercen contra las madres trabajadoras nace de estereotipos sociales que diferencian entre el trabajo «apropiado» para una mujer y para un hombre. Como tal, los trabajos orientados a los servicios, como el ambulantaje, son etiquetados por esas instituciones como «trabajo de mujer» (Elson 1999). En consecuencia, la municipalidad e IHNFA no reconocen la contribución productiva de las mujeres, ni han podido incorporar a este grupo de trabajadoras dentro de las agendas locales de desarrollo. 
Así las cosas, ni el mercado laboral ni las instituciones gubernamentales locales pueden «escapar al hecho [de] que alguien tiene que pagar por los niños» (Elson 1999: 612). En los próximos párrafos se expondrá cómo estas instituciones, en la práctica, operan de tal manera que provocan mayores desventajas para las mujeres a cargo de un hogar, quienes continúan con sus roles productivos en espacios públicos. Por mi parte, sugiero más allá: que el mercado y las instituciones gubernamentales no solamente resultan ser «portadoras de género», sino que además apoyan la inequidad de género. Dicho de otra forma, no hay nada de neutral en las estructuras del mercado; más bien argumento que son intencional y convenientemente negligentes en cuanto se refiere a las inequidades de género reinantes.

Entre la década de 1980 y 1990, América Latina en general pasó por una prolongada crisis económica - los países sufrieron severos ajustes fiscales y reestructuraciones-. Durante ese periodo, las economías informales y precarias crecieron, mientras los salarios caían y disminuía la protección social por parte del Estado. Como resultado de la globalización e integración económica, el mercado laboral en países como Honduras se volvió más heterogéneo, aumentando el atractivo del sector informal para aquellos en busca de alternativas con las que generar un ingreso. Esto se debió, en parte, a la insuficiente disponibilidad de empleo y exceso de oferta laboral urbanos como resultado de los cambios demográficos provocados por la migración del campo a la ciudad. Consecuentemente, en este periodo la pobreza se incrementó exponencialmente, al igual que el sector informal, entonces ocurrió la feminización de este sector. Para 2003, 66.6\% de la población femenina urbana activa en Honduras laboraba en el sector informal, el porcentaje más alto entre los países centroamericanos - en 2003 el porcentaje de mujeres empleadas en el sector informal era de 49.8\% en Costa Rica, 64.8\% en El Salvador, 61.3\% en Nicaragua, y 45.0\% en Panamá(OIT 2005). El efecto fue que las actividades económicas no reguladas proveyeron una opción para las trabajadoras independientes quienes, no obstante, enfrentaban mayor exclusión social al incorporarse a las economías informales.

A pesar del poco reconocimiento que puedan recibir las economías informales, el empleo urbano depende significativamente de las opciones que estas proveen, como el ambulantaje. En 2003, los trabajadores independientes y en microempresas - considerados activos dentro del sector informal - formaban 54.6\% del empleo urbano - Honduras sigue a Nicaragua con 58\%; los porcentajes de Nicaragua y Honduras son mucho mayores al promedio de toda Latinoamérica, 39.7\% - (OIT 2005). La Organización Internacional del 
Trabajo, OIT, reconoce que las economías formales e informales interactúan continuamente y dependen de los mismos mercados globales. La segregación de ciertos sectores continúa; sin embargo, Alter Chen (2001) señala que las mujeres que trabajan en el sector informal deberían ser consideradas e incluidas, especialmente en el diseño y evaluación de las agendas «contra la pobreza». La persistente exclusión de este sector de la población solamente intensifica una situación ya grave de rechazo social en donde el género, la informalidad y la pobreza, están íntimamente relacionados y se traslapan. Por tanto, debe darse un reconocimiento inicial de que el mercado laboral en áreas urbanas, espacio en el cual trabajan las mujeres vendedoras ambulantes, es un «mercado estructurado por prácticas, percepciones, normas, y redes sociales que [de hecho] son “portadoras de género"» (Elson 1999: 611).

\section{«LA MUJER» EN EL MARCO LEGAL NACIONAL E INTERNACIONAL}

La Organización Internacional del Trabajo es una de varias entidades internacionales de desarrollo cuyas políticas y agendas han trasladado sus intereses a temas relacionados con el bienestar de las mujeres y sus derechos. En 2000, convocó a la ejecución de una agenda que ponía mayor énfasis en la protección de la maternidad. Además, se propuso dirigir estos esfuerzos a grupos de mujeres que se encontraban dedicadas a trabajos «atípicos», en referencia específica a las mujeres en la economía informal. La OIT estableció que estas trabajadoras, por lo general, carecen de reconocimiento legal y salarios regulares, así como acceso a servicios asistenciales aprobados por la legislación nacional. Con esta agenda, la OIT se proponía que la población meta de sus proyectos de desarrollo fueran mujeres con ocupaciones como el ambulantaje, oficios domésticos privados y trabajadoras temporales en las industrias de maquila y agricultura. Los programas creados se enfocaban en la creciente vulnerabilidad hacia la pobreza y exclusión social que enfrentan las mujeres dentro del sector informal.

La OIT, así como otras organizaciones de desarrollo predominantes en la esfera internacional, han persuadido al estado de Honduras para que ratifique las convenciones cuya intención es incidir en el estatus subordinado y secundario en que viven las mujeres en el mundo. Entre las que han sido ratificadas están la declaración de los derechos humanos, la eliminación de toda discriminación contra la mujer e igual remuneración para la labor de la mujer y el hombre. Sin embargo, el estado de Honduras no se ha pronunciado en varias convenciones cruciales, como son la protección de la maternidad, políticas de empleo, la 
discriminación en el acceso a una educación, la discriminación social, el consentimiento para el matrimonio y la ciudadanía de la mujer casada. Pero hayan sido ratificadas o no, estas convenciones internacionales han tenido poco impacto en el ámbito local. A pesar de que se consideran leyes que están sobre la legislación nacional, su ratificación ha dado lugar a pocas o ninguna implementación práctica. El fracaso reside en el ajuste al marco legal nacional de dichas convenciones, lo que ha impedido su incorporación y regulación verdadera.

Por eso cabe mencionar la legislación nacional relevante por la cual se rigen y se justifican las políticas institucionales que de muchas maneras no consideran el estatus de exclusión social en el que se encuentran las mujeres hondureñas. El Código de la Familia, en vigencia, ratificado en 1984, todavía refleja el pensamiento tradicional de los legisladores que lo promulgaron. Esta ley aún incluye disposiciones patriarcales hacia la mujer, con lo cual la discriminación continua siendo «legalmente» aplicada. En esta ley hay cláusulas que declaran al Estado como el único protector de «la familia»y a las instituciones a través de las cuales se representa (e. g. IHNFA). Un ejemplo es el artículo 6, decreto 76-84: «La aplicación, interpretación, y dictamen de este código debería inspirar y ser inspirado por la unidad y fortaleza de la unidad familiar», y «estas leyes son del dominio del Estado, así como cualquier establecimiento oficial destinado a cumplir con tales fines». Aquí, la unidad familiar es identificada como representativa de un hogar biparental manejada por una persona femenina responsable de cuidarla y dirigida por un jefe de hogar y proveedor masculino.

Ha habido intentos de crear instituciones locales dedicadas a la protección de la mujer dentro de esta unidad familiar fuertemente idealizada. Ejemplos de tales iniciativas son los Centros de Consejería Familiar, creados en 1993 a través del Ministerio de Salud; la Fiscalía Especial de La Mujer, que se ocupa de los crímenes violentos contra la mujer, y la Política Nacional de la Mujer, lanzada en 1994 como resultado de un cabildeo político del Instituto Nacional de la Mujer, INAM. Este último logro incluye un plan de acción oficialmente sancionado para concretar avances sociales, económicos y políticos en beneficio de la mujer bajo la dirección del poder ejecutivo del Estado. Sin embargo, estas iniciativas y las instituciones que las lideran se encuentran en constante amenaza de desaparecer debido al poco interés en ellas por parte de los gobiernos y la consecuente falta de apoyo financiero.

En el Código del Trabajo, ratificado en 1995, también persisten medidas discriminatorias contra la mujer. Bajo el título III, el trabajo de la mujer en el mercado laboral es regulado bajo la clausula «Trabajo sujeto a regímenes especiales». En otras palabras, se 
considera que el trabajo y empleo de la mujer requiere de trato y consideraciones «especiales» debido a su «naturaleza». Estas circunstancias especiales de la mujer se refieren a su función biológica de reproducción y, en consecuencia, implica que el trabajo de la mujer también incluye las funciones sociales reproductivas. La ironía es que no se legisla por separado lo que concierne a la protección de aquellas mujeres trabajadoras que son madres, experimentan la maternidad o tienen que cumplir con las responsabilidades de la crianza de menores de edad y el cuidado de la casa. Esta misma cláusula especifica, además, que el trabajo de la mujer debe ser regulado de acuerdo con y comparable con el trabajo de los menores trabajadores. Es más, esta cláusula específica que la mujer y el menor de edad caen dentro de la misma categoría — cognitiva, moral y física — «de niños».

\section{EL INSTITUTO HONDUREÑO DE LA NIÑEZ Y LA FAMILIA}

El Instituto Hondureño de la Niñez y la Familia, IHNFA, es reconocido por el Estado como un organismo autónomo de desarrollo social cuya tarea principal es abogar por la protección de la niñez y promover el bienestar de los menores de edad dentro de la familia integral. Esto incluye jurisdicción sobre asuntos legales que involucran a la familia y la custodia de los menores. La Iglesia católica fomenta este ideal de familia integral, que consiste en la misma unidad familiar asumida y mencionada en el Código de Familia. Por lo tanto, la Iglesia tiende, por lo general, a condolerse de las madres solas, las madres pobres y las mujeres que trabajan en el sector informal (Chant 2003), vocalizando su preocupación con estas mujeres en asociación con la desintegración familiar, puesto que se les considera una amenaza no solo a la familia integral, sino también a la sociedad misma. En otras palabras, la Iglesia juzga a la familia no tradicional, liderada por mujeres solas jefas de familia que trabajan, como inaceptable debido a los riesgos sociales a que se exponen los menores de edad que crecen en esos hogares. Por lo tanto, la influencia de la Iglesia sobre la legislación nacional y la formulación de políticas ha resultado en recortes de los gastos sociales del Estado y reducción de la asistencia a las poblaciones más vulnerables (CDM 2005).

Como es evidente a partir de la declaración legal, el objetivo principal de esta organización es «velar por los derechos de los menores de edad» (Ley del IHNFA, Decreto 199-97). En esta declaración se encuentra implícita la suposición de que la familia es una unidad doméstica homogénea. El único interés de esta institución gira alrededor del bienestar de menores de edad sin ninguna referencia específica a asegurar el bienestar de padres y 
madres, específicamente para garantizar la protección de la mujer como parte de esa unidad familiar, a pesar de las consecuencias para el futuro bienestar de sus hijos. Las actividades de IHNFA están enmarcadas dentro de la normativa específica del Convenio Internacional de los Derechos de la Niñez, por el Código de la Niñez y Adolescencia (Decreto 73-96), y por el Código de la Familia (Decreto 76-84). Bajo estas premisas, a IHNFA le conciernen los derechos de la mujer únicamente como parte de una familia, en cuanto a su obligación de proteger y fomentar el desarrollo apropiado de los menores. Nuevamente en este caso se enfatiza la inherente adscripción de la mujer a las tareas de crianza y cuidado del hogar. Como tal, la institución está presente en la vida de mujeres que trabajan en la calle como una amenaza constante que les niega el derecho sobre la custodia de sus hijos y el derecho a trabajar como vendedoras ambulantes. El caso presentado al principio de este ensayo destaca la experiencia de una madre y vendedora ambulante, pero ella no es la única que ha vivido esta situación. El hecho de que todas las mujeres enviaron a sus hijos lejos ese día, mientras ellas se escondían de la gente del IHNFA, indica que todas ellas se consideraron en peligro de perder a sus hijos. La gente del IHNFA se enfocó en Roberta porque ella solía traer a su hija más menudo y porque su hija era mucho más pequeña que los demás menores presentes en la calle; así, por ende, más vulnerable. Sin embargo, la amenaza ese día era tangible para y compartida por todas las vendedoras ambulantes. De hecho María, quien vende periódicos en esa intersección, mencionó que si no fuera por su temor al acecho constante de la gente del IHNFA, ella traería a su hijo más a menudo y así trabajaría más horas, pues teniéndolo cerca no tendría que preocuparse por quién lo cuidaría en su ausencia.

La agenda de IHNFA ejemplifica un legado cultural que aún se mantiene en la sociedad contemporánea y que debe ser desafiado, puesto que es un legado de normas y valores familiares que todavía sostienen que «el matrimonio o la maternidad constituyen un destino del cual no hay escape para las mujeres y aquellas que no logran satisfacer este papel se arriesgan a ser catalogadas como "malas mujeres"» (Chant 2003: 167). Aquellas que son consideradas automáticamente malas madres, porque se les caracteriza como malas mujeres, son marcadas como tales por IHNFA. Este legado cultural de mala maternidad se refleja en los comentarios de Bessy sobre el incidente con IHNFA, en el cual emite un cierto juicio acerca de las acciones de Roberta y la considera una madre irresponsable. Bessy establece claramente sus prioridades como madre porque ella mantiene a su hija lejos de la calle, al contrario de Roberta. 
La reputación de esta institución corre de boca en boca en las calles, todos los vendedores ambulantes saben quién es la gente del IHNFA, y según algunos con los que hablé su tarea es aterrorizar a las madres trabajadoras de bajos recursos. Los comentarios de las vendedoras acerca de IHNFA manifiestan su familiaridad con la institución, que proviene de sus experiencias individuales no solo como madres, sino también como menores cuyas madres trabajaban de igual manera en las calles como vendedoras ambulantes. Estas mismas experiencias les han infundido temor y desconfianza hacia cualquier extraño que se les acerca, lo cual explica por qué en más de una ocasión las mismas vendedoras me acusaron de estar aliada con IHNFA; también explica por qué nuestra interacción nunca fue de completa confianza. El hecho de que la gente del IHNFA hiciera acto de presencia durante los primeros días de mis visitas en el sitio provocó grandes dudas sobre si ambos eventos serían una coincidencia.

Más allá de la reputación de IHNFA, estas mujeres lo reconocían como personificada en esas otras mujeres condescendientes vestidas sobriamente de traje, cuya actitud de superioridad se intuía mientras las intimidaban. Además, la autoridad legal del IHNFA sobre la maternidad es simbólicamente representada en los policías vestidos de fatiga militar que las acompañaban, portando armas visibles al salir del vehículo con vidrios oscuros para aprehender a las mujeres y niños desconcertados por el avance. Es más, la gente del IHNFA se presentaba en esta intersección bastante a menudo, por lo menos una vez cada tres meses; no siempre decomisaba los menores a las madres, en ocasiones solo se acercaban para advertirles a las vendedoras ambulantes que dejaran a sus hijos en casa o en la escuela. Sin embargo, mujeres como Roberta y Maribel seguían acompañándose de sus hijas, tal como otras tres mujeres que trabajaban al otro lado de la calle.

En el Sitio I, dentro del grupo entrevistado, cuatro de las cinco mujeres que trabajan de ambulantes han tenido experiencias previas con IHNFA, lo que sugiere que en realidad esta institución no reconoce como madres a estas vendedoras ambulantes ni las protege, muchas de ellas jefas de su hogar y parte esencial de la unidad doméstica, de la familia integral que han acuñado.

\section{LA MUNICIPALIDAD}

El gobierno municipal de la ciudad de Tegucigalpa está encargado de regular el trasporte privado y comercial, el desarrollo urbano, la recolección de impuestos, la seguridad 
ciudadana, además del mantenimiento adecuado y sanitario de los espacios y servicios públicos. Esta institución es responsable del mejoramiento de las condiciones de vida de la población más marginalizada y vulnerable del Distrito Central. Esto incluye proveer a sus residentes infraestructura de aguas negras, centros educativos, electricidad y agua potable, así como otras necesidades y servicios básicos. Todas las vendedoras ambulantes de ambos grupos, las entrevistadas, son residentes de barrios periféricos caracterizados por su aislamiento y carencias infraestructurales, sin medidas apropiadas de saneamiento -el acceso al agua potable es semanal-, ausencia de centros de atención infantil y altos índices de inseguridad y crimen.

Adicionalmente, han sido frecuentes las controversias entre el gobierno local y los vendedores ambulantes:

El día de ayer tuvo lugar un violento encuentro en el centro de Tegucigalpa, cuando agentes de la policía (DGIC) confiscaron miles de discos compactos clandestinos a los vendedores ambulantes ( $L a$ Tribuna, 24 de noviembre de 2006).

Una vendedora local ... reclamó ... «nadie nos dijo que nos iban a sacar de nuestros puestos de venta, solo nos dijeron que nos darían quince mil lempiras a cambio, pero eso no es suficiente para sustentar a nuestras familias, si quieren que nos salgamos de aquí nos tienen que proveer con una solución permanente para nuestras necesidades de ingreso y trabajo ... no nos vamos mientras no nos den algo más, de esto he subsistido por 20 años» (La Tribuna, 20 de febrero de 2007).

\begin{abstract}
Algunos vendedores ambulantes ... de la ciudad capital acamparon afuera del Congreso Nacional durante la noche para pedirle a los miembros del congreso que «les ayuden», estos reclaman que el acoso de las autoridades municipales se les está yendo de las manos ... los empleados municipales confiscan su mercancía ... [y] les imponen multas ilegítimas a los vendedores quienes, sin embargo, están siendo desplazados de las calles (La Tribuna, 8 de mayo de 2007).
\end{abstract}

Apostados en la quinta avenida ... entre empellones y toletazos, los vendedores protagonizaron un zafarrancho, mientras eran sometidos por la fuerza policial ... quemaron llantas y se tomaron la vía exigiendo la presencia de las autoridades municipales para exigirles una explicación ... estos capitalinos que ubican sus negocios de manera temporal frente a varios negocios de la zona, suman unos 2 mil y tienen permiso de la gerencia de mercados para colocar sus puestos en un espacio de la tercera avenida ... «No nos dejan trabajar, desde las 4:00 de la mañana ellos llenaron de policías toda la quinta avenida como si nosotros fuéramos delincuentes, simplemente queremos trabajar ... habemos personas que quitamos dinero prestado para poder montar un negocito», dijo molesto un vendedor que se abstuvo de dar su nombre, según él por temor a represalias (El Heraldo, 18 de diciembre de 2008). 
Marti (1990) anota que la remoción de los vendedores ambulantes de las calles de la ciudad por los gobiernos locales es una reacción a los medianos empresarios, quienes consideran que estos vendedores son una competencia injusta. Al mismo tiempo, los vendedores ambulantes son considerados la epitome del antimodernismo y promotores del retraso en la economía. Estas percepciones no toman en cuenta las intrincadas redes de intercambio (Tamar 1998) que involucran tanto a los distribuidores a mediana y gran escala y las trasnacionales, como a los mercados informales. Dentro de estas redes, unos dependen de otros para alcanzar éxito financiero.

Sin embargo, en años más recientes los esfuerzos de la municipalidad se han centrado en limitar las actividades del mercado informal a través de la remoción de los vendedores ambulantes, demandar el pago de impuestos y permisos de operación y amenazar con poner un fin a sus transacciones, confiscando las mercancías sin proveer ninguna solución negociada para que los vendedores asimilen los cambios. La notoria presencia de la municipalidad en el Sitio II, donde se entrevistó a un grupo de ocho mujeres, recordaba constantemente a los vendedores ambulantes el carácter ilegal de su actividad. La municipalidad circulaba por este sitio todos los días en un vehículo de brillante color naranja, lleno de policías que patrullaban las calles mientras con la sirena intentaban abrirse paso en el intenso tráfico. El vehículo mostraba calcomanías con frases como «Su amigo», «Estamos aquí para servirle», «Seguridad y protección». Irónicamente, las vendedoras ambulantes se reían de tales frases al ver pasar la patrulla. Por mi parte, no había puesto mucha atención a los logos que los empleados de la municipalidad llevaban en sus uniformes o en las patrullas hasta que Ana y Sandra soltaron risas repitiendo en voz alta la frase: «Su amigo». Unos momentos después Sandra añadió, «no hay nada de eso con esa gente». Por el contrario, la constante presencia de las patrullas irritaba al extremo a las vendedoras y las mantenía en estado de alerta por sus puestos de venta. Ramona explicaba que ella siempre se encontraba «a la expectativa», asegurándose que tanto su puesto como la acera se mantuvieran limpios y sin causar obstrucciones que pudieran impedir el paso, ya que esto llamaba la atención de los de la municipalidad sobre todos y cada uno de los que vendían en la calle. Lo que significa dejar la basura en contenedores, barrer la acera con frecuencia y esconder la mercancía cuando tomaban un descanso. El asunto de la basura, en particular los residuos asociados con pelar y preparar mangos, era motivo de discusiones entre Ana, Sandra y Ramona, ya que 
Ramona siempre les estaba llamando la atención de ello. También surgían desacuerdos menores sobre a quién pertenecían las cáscaras de mango después de la última ronda de limpieza, antes de partir todas para sus casas. La preocupación de estas vendedoras tenía que ver con el riesgo de perder la venta del día, o del mes entero, si por alguna razón la policía consideraba que obstruían a los peatones o ensuciaban la calle y la acera, como era el caso de otros vendedores en otros sectores de la ciudad. De ahí que el mantenimiento limpio y ordenado de la acera era una parte importante de la rutina diaria.

Los gobiernos estatales se enfrentan a la presión de combatir contra economías informales, lo cual sumado a la falta de investigaciones, interés y manejo apropiado de la situación, ha generado campañas nacionales de extrema hostilidad en contra de personas que se encuentras inmersas en este sector (Ziccardi 2005). En general, las estrategias de los gobiernos municipales son una reflexión de tales campañas que, sin embargo, han sido intentos inútiles en cuanto a un abordaje adecuado de la existencia de vendedores ambulantes en el área urbana. En el ámbito local, los vendedores ambulantes han sido insertados dentro de una estrategia enfocada en la remoción y cierre de sus actividades económicas, como un mal que infesta las calles. Por otra parte, anteriores gobiernos municipales han reconocido la necesidad de mejorar los proyectos de autofinanciamiento de las mujeres para fomentar microempresas comunitarias y familiares dirigidas por ellas y generar un medio de subsistencia para sus familias. Sin embargo, el actual gobierno municipal no ha mostrado capacidad de integrar proyectos de microempresa con el trabajo de las mujeres en las calles, a través del cual ellas generan su propio empleo. Esta parecería una fórmula razonable de incorporar a las vendedoras ambulantes en algún tipo de actividad formal relacionada con sus actividades de subsistencia. A pesar de las circunstancias desalentadoras comentadas, hay mujeres que siguen valiéndose de la informalidad para ganarse la vida, enfrentándose en el proceso a la oposición del gobierno municipal. En consecuencia, no sorprende que desde la perspectiva de estas vendedoras ambulantes, la agenda de desarrollo y urbanización de La Municipalidad «solamente privilegia a los ya privilegiados».

\section{VIVIENDO LA EXCLUSIÓN SOCIAL}

Para colocar las experiencias personales de las mujeres en el ambulantaje en la plataforma de discusión, es necesario establecer la conexión entre el mercado laboral informal como portador de género y las amenazas con la sistemática negligencia institucional de que son 
objeto las mujeres en lo local. Una asociación entre éstas es la exclusión social de las mujeres. Tanto la faceta económica como la política del mercado y de las instituciones públicas, respectivamente participan en la construcción social y cultural de las mujeres y su espacio de trabajo, los cuales han mostrado la tendencia de fomentar las percepciones tradicionales sobre los roles e identidad de las mujeres en nuestra propia cotidianidad.

Se entiende por exclusión social

La inhabilidad de un individuo de participar en el ... funcionamiento de la sociedad en la que vive ... es la negación del acceso equitativo a oportunidades, impuesta por ciertos grupos de la sociedad sobre otros ... grupos culturalmente definidos ... entroncados en las interacciones sociales (Buviniç y Mazza 2006: $3-4)$.

Hay varias instancias en la exclusión social así definida entre estas vendedoras ambulantes; buena parte de esta exclusión prevalece más en relación con su existencia y presencia como ciudadanas residiendo en la ciudad. Sus condiciones de vida son testimonio de su estado de segregación y su negación por parte del gobierno local y de la sociedad en general. Todas las mujeres entrevistadas en ambos sitios viven en barrios muy alejados y abandonados. El hogar de Bessy, que tuve oportunidad de visitar, consistía en un cuarto arrendado en un segundo piso, rodeado por un muro de ocho metros de altura. En ese espacio cocinaba, dormía y descansaba en sus horas de ocio junto con su hija y su hermana menor; el área es conocida por la frecuente violencia relacionada con las pandillas y el tráfico de drogas. Las mujeres solas con hijos, como Bessy, viven en zonas que les hacen tomar conciencia del alto grado de inseguridad reinante a su alrededor, lo cual se refleja en la descripción que Bessy ofrece de los acontecimientos que se suceden en su vecindario. Los jóvenes pandilleros trafican con armas y drogas, a la vez que asaltan y roban. Las medidas de protección que tomó durante mi visita hicieron darme cuenta del temor que invade en todo momento su vida, hasta que se ha vuelto cotidiano. Mi presencia distintiva en su vecindario y en su hogar y el recorrido en su compañía por las veredas me alertó sobre la mayor precariedad que mi misma visita le podía provocar.

A Bessy se le dificulta encontrar servicios de salud y guarderías para el cuidado de su hija, ya que dentro de estos vecindarios los servicios públicos son muy ineficientes. Además, la gente de la ciudad parece estar negativamente predispuesta hacia tales comunidades, lo cual se trasfiere directamente a personas como Bessy; como individuos que se esmeran en su 
trabajo, son padres responsables y no están relacionados con las maras. La situación de Roberta es aún más precaria, ya que nunca sabe si tendrá suficiente dinero para pagar por una noche en una cuartería. Roberta me ha comentado de ocasiones en las cuales se le ha rehusado estadía en un cuarto porque se sospecha que no tiene el dinero para pagar, que destruirá el cuarto, o que usa el cuarto para llevar a cabo transacciones sexuales. Es más, ha habido ocasiones en las cuales sus pertenencias son desalojadas del cuarto que alquila, o ha regresado a su cuarto en la noche para encontrar que sus pocas pertenencias han sido movidas. Si tiene suerte, alquila otro cuarto y se traslada a él por esa noche; ya que solo se le permite alquilar un cuarto por una noche a la vez. Este resulta el mejor ejemplo de discriminación social, lo cual mantiene a una mujer trabajadora con hijos viviendo prácticamente en las calles, aun cuando ella tiene el dinero para pagar por un techo que les albergue.

Los efectos de la exclusión social que trascurre en las vidas de las vendedoras ambulantes entrevistadas se ejemplifican en el caso de Roberta, quien lucha por identificarse positivamente como una madre trabajadora. Todo intento y esmero de Roberta por conseguir dinero para ella y su hija es constantemente juzgado por sus compañeras vendedoras ambulantes, por peatones que pasan todos los días, por clientes, y por IHNFA; tanto así que se le hace imposible ser una trabajadora apropiada — porque también mendiga — o una buena madre - porque concientemente se presenta con su hija como una víctima para poder vender más y recibir más caridad-. Sin embargo, considera que estas estrategias son beneficiosas, aun cuando no parezca claro si este es un oficio que ella escogió o un oficio que la acogió. Roberta empieza todos sus días temprano y pasa largas horas de la noche trabajando en la calle, todos los días de la semana, sólo para poder conseguir suficiente dinero para el alquiler de un cuarto que se le niega. Al no ser reconocidos sus derechos sociales y económicos, vemos cómo la labor productiva y reproductiva de una mujer es alienada de la construcción de una imagen positiva de ella misma como madre y proveedora.

\section{DESDE LA VIOLENCIA ESTRUCTURAL A LA DISCRIMINACIÓN INSTITUCIONAL}

El concepto de exclusión social ha sido definido (Sen 2000, Silver y Miller 2003, Das y Poole 2004, Ziccardi 2005) de tal manera que resulta lo suficientemente flexible en su consideración e inclusión de variadas circunstancias de discriminación y privación que incluyen: seguridad de subsistencia, empleo y salario estables, vivienda, educación y 
competencia, equidad legal, entre otros. La sección anterior ha ilustrado cómo las vendedoras ambulantes en la urbe dentro del contexto hondureño experimentan estas formas de exclusión conjuntamente. Lo que «es una tipología de causalidad» (Sen 2000: 10), ya que resulta de un proceso cíclico que aumenta diversas formas de exclusión social.

Ziccardi (2005) también comenta que hay numerosos factores de riesgo social que permiten operacionalizar el concepto de exclusión social, algunos son: el acceso a crédito, el acceso a empleo, el acceso a servicios sociales, el analfabetismo, la pobreza, la marginalización geográfica, la discriminación de género, la discriminación política... Las vendedoras ambulantes entrevistadas presentan varios de estos riesgos sociales. Por ejemplo, en el Sitio I, solo dos de las cinco mujeres habían pasado de quinto grado; las tres restantes, las más jóvenes del grupo, cursaron entre tercer y sexto grado. En el Sitio II, las mujeres son parcialmente alfabetas, todas han cursado al menos tercer grado, solo Ramona y Jessica se graduaron de sexto grado y siguieron estudiando. $\mathrm{Y}$ aun cuando estas mujeres se reconocen como pobres, también demuestran que hay diferentes escalas de pobreza entre los/las que se encuentran vendiendo en las calles.

En la sección anterior se mencionó a dos instituciones gubernamentales para demostrar que hay poca representación política de los intereses de mujeres que son empresarias, ciudadanas, y miembros integrales de sus familias. También se ha expuesto que los mercados económicos - laborales - están organizados de tal manera que el empleo de la mujer sigue siendo bastante restringido, devaluado y alienado. Así que las vendedoras ambulantes presentan un caso multifacético y de varias escalas — estructurales e institucionales - de exclusión social saturadas por verdadera vulnerabilidad a la pobreza e inequidad.

La exclusión social es parte de la vida diaria de las vendedoras ambulantes, quienes están muy al tanto del estigma y discriminación asociados con su trabajo; colectivamente se les asocia negativamente con la economía, ellas añaden a los atributos negativos de la informalidad. Esto, sin duda, tiende a influenciar sus oportunidades de vida. Es más, «este estigma asocia las diferencias compartidas entre personas de un grupo con atributos negativos que "nos" separan de "ellos", lo cual reduce "su" estatus. Las diferencias de poder son la base de este estigma» (Buviniç y Mazza 2006: 6). Las mujeres entrevistadas, por ejemplo, eligieron mantenerse lejos de otras opciones de trabajo debido a experiencias previas. María trabajó como mesera y le pagaban «bajo la mesa». A ella no le gustaba por las horas tardes e inconsistentes del trabajo, y porque tenía que viajar largas distancias y a horas peligrosas de 
la noche, lo cual evitaba que pudiera cuidar de su hija más pequeña. Sandra comentó que ella nunca sería una doméstica ya que lo que pagan no vale la pena, además es trabajo que de todas maneras debe hacer en su propio hogar. Ramona mencionó que prefería ser vendedora ambulante antes que su trabajo previo en un supermercado, porque había que marcar tarjeta y debía mantener su matrimonio en secreto, ya que su marido trabajaba en el mismo local y este tipo de relaciones entre empleados estaba prohibido.

Algunas de estas mujeres simplemente no podían optar a trabajos más formales porque no tenían la documentación e identificación adecuadas, lo cual les prohibía aplicar a estos trabajos, registrar a sus hijos, conseguir cuidado del seguro social, y también impedía que votaran. Bessy y Roberta, por ejemplo, no portaban ningún tipo de identificación oficial. Bessy quería trabajar en una maquila, pero no podía siquiera llenar el formulario de aplicación ni tomar el examen de agilidad sin la identificación necesaria. Además, muchas eran muy concientes del tipo de competencia en ese trabajo y de las exigencias requeridas de las maquiladoras. Algunas mencionaron que no valía la pena intentar aplicar para tales trabajos; así obviaban tener que llenar formularios que no podían leer y evitaban el rechazo al no pasar el examen de agilidad. Esto reflejaba instancias de auto discriminación (Buviniç and Mazza 2006: 5), en esos momentos que ellas dudaban de sus aptitudes y habilidades para ejercer tal trabajo ellas mismas se mantenían al margen y se excluían de otras opciones de trabajo formal. Solo María había llenado la aplicación, pero no pasó el examen de agilidad. A pesar de que falló quería volver a intentarlo, aun cuando la idea de tomar el examen le provocaba mucho nerviosismo.

La acusación de robo constituía otra de las razones por las cuales la opción del trabajo doméstico era rechazada. Sandra y Ana se rehusaban a volver a trabajar como domésticas porque las patronas siempre las acusaban de ladronas. Las mujeres entrevistadas sabían de muchas mujeres que habían sido acusadas de robo, también mencionaban que este tipo de trabajo amenaza la sexualidad de mujeres jóvenes y niñas. Es precisamente por eso que las mujeres entrevistadas escogieron permanecer en el ambulantaje, debido a experiencias desalentadoras que habían tenido. Roberta comenta:

Yo digo que voy a seguir como vendedora ambulante. No quiero otro trabajo porque dicen que no paga, [mi Mami] trabajó de eso y a ella se fueron debiéndole un montón de dinero y la trataron de ladrona cuando a ella no le gusta tocar lo ajeno. 
En sus comentarios parece evidente que reconocen la explotación de los trabajos disponibles, y valoran mucho su libertad como para optar por un trabajo como doméstica, en maquilas, o en el sector de servicios.

Hasta el momento hemos visto que en contextos urbanos de Honduras a las mujeres se les considera como una parte intrínseca de la unidad doméstica y del concepto de familia. En Latinoamérica a esta unidad doméstica se le considera como el punto focal de estabilidad de la sociedad, mediante el cual las economías, culturas y políticas, son institucionalizadas y legitimizadas. Si tomamos en cuenta que estas vendedoras ambulantes viven y trabajan dentro de un contexto en el cual «la mujer es el agente universal de la socialización ... ella es la personificación de las funciones domésticas» (Ortner 1985: 84-85), entonces podemos entender por qué las mujeres enfrentan mayor supervisión, restricciones y circunscripción. Así que no es casualidad que los mercados laborales y los gobiernos locales sean negligentes de la realidad de las mujeres como ciudadanas productivas. El rol de las mujeres dentro del ámbito privado es naturalizado y justificado por nada más que su habilidad biológica de reproducción. Esta es la «naturaleza» de la exclusión social de las mujeres, la discriminación no se debe a su informalidad sino a su género. Según Buviniç y Mazza (2006) la exclusión social proviene de procesos arbitrarios de segregación que tienden a aislar a personas no por lo que hacen sino por quienes son. Así que el problema de la discriminación contra estas mujeres no reside en la informalidad de su oficio; la discriminación reside en su género. En muchos casos, este tipo de discriminación y exclusión se replica en siguientes generaciones de mujeres, en consecuencia produce una creciente acumulación de abandono social y político.

Parece claro que las vendedoras ambulantes entrevistadas han sido receptoras de una acumulación cíclica de exclusión social, pero está por verse si esto se multiplicará en las vidas de sus hijas. Las mujeres que participaron en este trabajo de investigación sugieren que la vida de sus hijas e hijos será diferente y mejor. Estas mujeres mantienen grandes expectativas y logros para la siguiente generación, y en algunos casos estas mujeres ya han sido testigos de algunos de ellos y avances de sus hijos e hijas. 


\section{PELIGROS E INCENTIVOS:}

\section{¿POR QUÉ CONTINUAR SIENDO UNA VENDEDORA AMBULANTE?}

Los riesgo inmediatos y más obvios que conlleva trabajar en las calles para estas mujeres son: 1. el constante peligro de perder custodia sobre sus hijos; 2. aprehensión y encarcelamiento temporal; 3. pérdida de mercadería por su confisca; 4. la experiencia de encuentros violentos y traumáticos con la ley; 5. una cotidiana desconfianza debido a la secreta y constante supervisión; 6. exponerse al trato indiferente y corrupto de las autoridades.

Después de la primera visita de IHNFA, Roberta desapareció por varios días. Al principio Roberta regresó a vender a la mediana sin Sofía, pero eventualmente empezó a traerla. Durante una entrevista le pregunté si ella estaba preocupada porque IHNFA regresara a quitarle su hija; ella respondió: «Me da miedo, pero mi diosito me la tiene que cuidar». El específico que he descrito me ha provocado reconsiderar por qué mujeres como Roberta prefieren una forma de trabajo que parece tan inestable e insegura y cómo justifican los riesgos involucrados, en especial cuando consideramos el uso simbólico de fuerza mediante el cual se ejerce la discriminación contra estas mujeres. La internalización de imágenes que provocan temor al ser proyectadas por figuras de autoridad es parte de la presencia de IHNFA y del gobierno municipal, lo que provoca duda y desconfianza en las vendedoras ambulantes. El uso de armas por los policías en fatiga, por ejemplo, es intencional de poder para evocar temor en el ámbito público al enfatizar en la estigmatización y criminalización de las vendedoras ambulantes.

Los riesgos involucrados en ser una vendedora ambulante son graves; y aun así este trabajo satisface las responsabilidades de una madre proveedora y de una trabajadora autosuficiente. Bajo las prescripciones laborales y sociales mencionadas, estas mujeres no pueden ser ni madres ni trabajadoras «ideales». No obstante, las circunstancias bajo las cuales estas mujeres se hallan trabajando en las calles tampoco son ideales, inclusivas o equitativas. Las vendedoras entrevistadas no se consideran trabajadoras ilegales o malas madres. Sandra justifica su trabajo al reconocer que cualquier persona en su circunstancia haría lo mismo para sobrevivir. A través de su oficio estas mujeres adquieren ingresos para satisfacer sus necesidades inmediatas, controlan sus rutinas de trabajo, son autónomas en su toma de decisiones, y le atribuyen un alto valor agregado y afectivo a su trabajo. Estos factores influyen notablemente en su motivación y preferencia por ser vendedoras ambulantes. 
Aun cuando estas mujeres prefieren ser vendedoras ambulantes, ellas han previsto un futuro distinto para sus hijos e hijas. Roberta, por ejemplo, menciona sus expectativas para el futuro de Sofía:

\begin{abstract}
Solo porque yo soy «analfabeta» no significa que mis hijos deberían ser también ... eso no significa que mis hijos van a ser como yo ... No quiero que ella [Sofía] sufra ... Cuando crezca la voy a meter [a la escuela] también, primero Dios. Yo quiero que ella crezca con estudios para que no vaya a ser igual a mí. Los estudios la van a ayudar porque el día de mañana no quiero que vaya a decir «por tu culpa me quedé analfabeta»... [Ella] va a ir a la iglesia ... no quiero nada de puesto, ni venta para ella [sino] un trabajo honrado como en un banco, eso es lo que le pido a mi Dios.
\end{abstract}

Barker y Knaul (2000) comentan que el tener expectativas de un mejor futuro, así como una buena autoestima, ayuda a que estas mujeres prevalezcan exitosamente cuando se ven en circunstancias difíciles. La resolución de adquirir una vida diferente y mejor para sus hijos e hijas satisface sus aspiraciones personales. En el éxito de sus hijos se refleja su éxito personal como individuos productivos de sus hogares y de la economía nacional.

Sin embargo, también hay momentos en las conversaciones con Roberta en que el futuro éxito de sus hijos no es suficiente para llenar las expectativas de su propia vida:

Hasta que tenía 22 años pude regresar otra vez a la escuela, pero no me quisieron aceptar porque estaba embarazada. Regresé porque quería mejorar, aprender y enseñarle algo a mis hijos, pero no pude.

Aquí vemos la exclusión social latente en la vida de Roberta; se le niega la oportunidad de participar en el sistema de educación pública, se le estigmatiza por estar embarazada, se le evita poder trasmitir conocimiento a sus hijos, y es así que deliberadamente se le prohíbe poder mejorar su propia condición de vida.

Estos comentarios son un recordatorio de que estas son mujeres «guiadas por decisiones muy racionales, hacen lo mejor que pueden bajo circunstancias de desesperanza y carencia» (Arizpe 1977: 35). Las vendedoras ambulantes entrevistadas son concientes de las prácticas negligentes de instituciones globales - i. e. el mercado laboral- y locales - i. e. IHNFA y gobierno municipal-, de igual manera saben muy bien cuáles son los riesgos a los que se enfrentan dentro del sector informal. Sin embargo sigue siendo razonable, que dentro de los contextos particulares que he descrito, el que estas mujeres hayan escogido la venta ambulante como mejor opción dentro de las alternativas ofrecidas por el sector informal. 


\section{CONCLUSIONES}

Al concluir con mi trabajo de campo, regresé a despedirme de las vendedoras ambulantes del Sitio I. Ese día las mujeres estaban muy renuentes a platicar conmigo. Finalmente, Bessy se me acercó y me reclamó que si yo había tenido algo que ver «con lo de Roberta». Yo no estaba segura a qué se refería. Ella me explicó que dos días antes IHNFA había regresado y se llevó a Roberta y a Sofía. A Roberta la interrogaron varias horas, durante el interrogatorio le mostraron fotos que habían tomado de ella, de su hija, de otras vendedoras, y de mí. Unos días más tarde averigüé que Roberta había perdido la custodia de su hija, y esta vez no habría manera de recuperarla debido a su repetido historial. Los padres de Roberta intentaban adquirir la custodia de Sofía para que no fuera a un orfelinato.

Las coincidencias de la vida son tales que poco después me encontré con el papá de Roberta, quien trataba de conseguir un certificado de nacimiento para Sofía pero el guardia de la oficina pública no lo dejaba pasar. Él me reconoció y me pidió el favor de conseguirle los documentos. En ese momento me di cuenta que era mi oportunidad de retribuirle a Roberta por la confianza que me había brindado. Conseguir el documento, para mí fue muy sencillo, unos días más tarde la Corte le otorgó custodia de Sofía a los padres de Roberta.

Así que como en el caso de los dos hijos mayores de Roberta, Sofía ahora está bajo la tutela y responsabilidad legal de sus abuelos. Roberta aún es su madre, aunque estos acontecimientos modifiquen lo que eso realmente significa para ella y para sus hijos en el futuro.

El caso de Roberta, aunque excepcional, es el caso de todas, ya que son compañeras de trabajo; todas han cuidado a Sofía, y todas temen perder a sus hijos y terminar en la cárcel. Las experiencias descritas han provocado que estas vendedoras ambulantes se distancien de los que no son parte de este mundo de informalidad, lo cual incrementa su estado de exclusión social. A la vez, lo que las motiva a permanecer en la venta ambulante son las interacciones sociales y genuinas entre vendedoras y sus hijos e hijas.

Ahora Roberta debe renegociar lo que significa ser una madre, una buena madre, cuando ya no tiene custodia legal sobre su hija, pues se le ha juzgado como una madre incapaz de cuidarla. Sin embargo, el ser vendedora ambulante es lo que ha permitido que Roberta se identifique como una buena madre, mientras redefine lo que es la buena maternidad como una mujer que trabaja de vendedora ambulante en la calle. 
En este ensayo he presentado las limitaciones constantes que enfrentan las vendedoras ambulantes como mujeres trabajadoras y madres. Las condiciones estructurales que aún persisten no solo feminizan el sector informal, si no también intentan justificar el presente problema de la feminización de la pobreza en Latinoamérica. En esta ponencia he intentado sacar a relucir instantes de resistencia y autodeterminación de estas mujeres que optan por ser vendedoras ambulantes. Al convertirse en parte significativa del sector informal, de igual manera se convierten en receptoras de la violencia estructural de mercados laborales mundiales y de prejuicios patriarcales de instituciones nacionales. Espero que este escrito lleve a una reflexión sobre los procesos de feminización en la esfera global, que en el ámbito local fomentan experiencias de inequidad entre madres pobres trabajando en espacios urbanos. 


\section{BIBLIOGRAFÍA}

Alter Chen, Martha, 2001, «Women in the Informal Sector: A Global Picture, the Global Movement». SAIS Review, vol. 1, núm. 21, pp. 71-82.

Arizpe, Lourdes, 1977, Women in the informal sector: The case of Mexico City. University of Chicago Press, Chicago.

Barker, Gary y Felicia Knaul, 2000, Urban Girls: Empowerment in Especially Difficult Circumstances. Intermediate Technology Publishing, Londres.

Bustos, Beatriz, 1994, El trabajo femenino en América Latina: Los debates en la década de los noventa. Universidad de Guadalajara, Guadalajara, México.

Buviniç, Mayra y J. Mazza, 2006, «Gender and Social Inclusion: Social Policy Perspectives from Latin America and The Caribbean». Arusha Conference, New Frontiers of Social Policy, 12-15 de diciembre de 2005.

Centro de Documentación de Mujeres, CDM, 2005, Mujeres en Cifras. Ministerio de la Mujer, Honduras.

Chant, Sylvia, 2003, Gender in Latin America. Rutgers University Press, New Brunswick.

Das, Veena y Deborah Poole, 2004, Anthropology in the margins of the state. School of American Research Press, Santa Fe.

Elson, Diane, 1999, «Labor Markets as Gendered Institutions: Equality, Efficiency and Empowerment Issues». World Development, vol. 3, núm. 27, pp. 611-627.

Marti, Judith, 1990, Subsistence and the State: Municipal Government Policies and Urban Markets in Developing Nations. Prentice Hall, New Jersey. 
OIT, 2005, «Informal Employment in Latin America». En http://www.ilo.org [consultado el 20 de abril de 2008].

Ortner, Sherry, 1985, «Sexual Meanings: the cultural construction of gender and sexuality». Cambridge University Press, Cambridge.

Pincus, Fred, 1996, «Discrimination Comes in Many Forms». The American Behavioral Scientist, vol. 2, núm. 40, pp. 186-195.

Raffaelli, Marcela, 2000, «Gender differences in Brazilian street youth's family circumstances and experiences on the street». Child Abuse \& Neglect, vol. 11, núm. 24, pp. 1431-1441.

Safa, Helen, 1995, «Economic restrusturing and gender subordination». Latin American Perspectives, vol. 2, núm. 22, pp. 32-50.

Sen, Amartya, 2000, «Social Exclusion: Concept, Application, and Scrutiny». Social Development, paper núm. 1. Asian Development Bank.

Silver, Hillary y S. M. Miller, 2003, «Social Exclusion». Indicators, vol. 2, núm. 2, pp. 1-17.

Takemi, Keizo, 2002, «Evolution of the Human Security Concept». Ponencia presentada en Fourth Intellectual Dialogue on Building Asia's Tomorrow. En http://www.jcie.org/researchpdfs/HealthHumSec/health_takemi.pdf [consultado el 10 de diciembre de 2008].

Tamar Wilson, Sandra, 1998, «Approaches to Understanding the Position of Women Workers in the Informal Sector». Latin American Perspectives, vol. 2, núm. 25, pp. 105-119.

Ziccardi, Alicia, 2005, «Las ciudades y la cuestión social». Instituto de Investigaciones Sociales, UNAM, México. 
Fecha de recepción: 22 de mayo de 2009.

Fecha de aceptación: 10 de agosto de 2009. 